\title{
ENZYME REPLACEMENT THERAPY IN PORPHYRIAS - IV. FIRST SUCCESSFUL HUMAN CLINICAL TRIAL OF $\delta$-AMINOLEVULINATE DEHYDRATASE-LOADED ERYTHROCYTE GHOSTS
}

\author{
Alcira M. del C. Batlle ${ }^{1}$, Norma L. Bustos ${ }^{1}$, Ana Maria Stella ${ }^{1}$, Eva A. Wider ${ }^{1}$, \\ Honorina A. Conti ${ }^{2}$ and Armando Mendez ${ }^{2}$ \\ 'Centro de Investigaciones sobre Porfirinas y Porfirias, CIPYP (CONICET y FCE y N. University of \\ B. Aires), Ciudad Universitaria, Pabellón II, 1428 Buenos Aires, Argentine \\ ${ }^{2}$ Unidad B-4 de Clínica Médica, Hospital Ramos Mejía, Gral. Urquiza 609, 1221 Buenos Aires, Argentine
}

(Received 17 January 1983)

\begin{abstract}
A patient with chronic lead intoxication was treated with only one course of highly purified human blood aminolaevulinate dehydratase entrapped in autologous erythrocyte ghosts given intravenously.

2. No untoward effects were observed during or after infusion.

3. An immediate increase in the patient's erythrocyte dehydratase activity was detected $1 \mathrm{hr}$ after enzyme administration, reaching its maximum and nearly normal level 2 days later, values remained unchanged for a week, to slowly diminish after 2 weeks of initiated the treatment, and finally recovered activity was kept practically leveled off for weeks.

4. This novel therapeutic trial produced complete improvement both clinical and biochemical, showing that enzyme infusion has been beneficial and can be safely and successfully used in the treatment of human lead intoxication.
\end{abstract}

\section{INTRODUCTION}

Enzyme replacement therapy of genetically inherited disorders has received increasing attention (Ryman, 1977). We have extended its possibilities to the field of porphyrias, which are in fact both hereditary and acquired disturbances in porphyrin metabolism. In each type of porphyria a specific and single enzyme is partially defective, leading to an abnormal and characteristic biochemical pattern of accumulation and excretion of porphyrins and/or precursors. Therefore, we became enthusiastic in the application of enzyme therapy in these diseases, an approach not yet tried before (Bustos et al., 1980, 1983a; Espinola et al., 1983).

In order to successfully apply enzyme replacement therapy, some criteria must be fulfilled: (i) a suitable carrier for the enzyme, which protects both the enzyme from degradation and inactivation and the host from unwanted pharmacological and immunological effects, should be developed; (ii) a source of enzyme should be selected, this aspect is of major importance, and, when planning to be used in human therapy, it should be of human origin; (iii) the preparation of the enzyme should be of the highest purity possible and very stable; (iv) the enzyme should be delivered to the tissue in which it is to function; (v) the enzyme should interact with its substrate long enough to render clinical benefits.

In selecting the porphyria to start trying enzyme replacement therapy, we chose lead intoxication,

Address for correspondence: Professor Alcira Batlle, Viamonte 188110 A, (1056) Buenos Aires, Argentine. because of many considerations. It is a disorder which occurs with high frequency, consequently it would be easy to find suitable test subjects and also the number of people benefiting would be important. It is one of the most advantageous experimental animal models. An important biochemical abnormality in lead poisoning is an increased concentration of $\delta$-aminolaevulinic acid (ALA), very easily detected in urine, as a consequence of a significant inhibition of ALA-dehydratase (ALA-D) by the metal; measurement of erythrocyte ALA-D activity is the most sensitive indicator of lead exposure.

Therefore, a procedure for obtaining a highly purified and stable preparation of ALA-D from human blood has been developed (Bustos et al., 1980).

The potential use of erythrocytes as carriers for ALA-D was investigated and we found that resealed erythrocyte ghosts can function as such, entrapping the enzyme with high yield and activity and delivering it to the desired target sites in the very cells which produce the metabolic disruption (Bustos et al., 1983a).

Results on animal models, showed that it was possible to correct both in vitro (Bustos et al., 1983a) and in vivo (Bustos et al., 1983b) the activity of defective erythrocytes by incorporating exogenous human enzyme, indicating that the cell ghosts loaded with human ALA-D could be useful for treatment of human lead intoxication.

We now report clinical and laboratory findings in a patient with chronic lead intoxication whom we have treated with human blood ALA-D entrapped in his own red cell ghosts. 


\section{MATERIALS AND METHODS}

\section{Blood samples}

Normal human blood (31) for enzyme purification was obtained from the Blood Bank of Ramos Mejia Hospital, Buenos Aires. Patient's blood $(500 \mathrm{ml})$ was withdrawn directly into a standard blood bag containing heparine.

\section{Purification of human blood $A L A-D$}

This was carried out following the procedure described by Bustos et al. (1980). ALA-D activity was assayed according to Batlle et al. (1965) along the steps of the purification procedure or to Bustos et al. (1983a) when measured in both intact erythrocytes and ghosts. One unit of ALA-D is defined as the amount of enzyme catalysing the formation of $1 \mathrm{nmol} \mathrm{PBG} / \mathrm{h}$; activity will be expressed either as Units/mg protein (U/mg) or Units/ml of packed red cells (U/ml). Porphyrins and PBG were measured by the method of Rimington (1971) and ALA by that of Mauzerall and Granick (1956). Blood lcad was determincd by flamcicss atomic absorption spectrophotometry following a procedure similar to that described by Kesten et al. (1980).

Preparation of autologous erythrocyte ghosts containing $A L A-D$

Red blood cell ghosts containing ALA-D (RBCg(ALAD)) were prepared from $500 \mathrm{ml}$ of patient's own blood, following the technique described by Bustos et al. (1982), yielding $100 \mathrm{ml}$ of ghosts, which were suspended in equal volume of isotonic saline (activity $2.47 \mathrm{U} / \mathrm{mg}$ or $128.4 \mathrm{U} / \mathrm{ml}$ ), and returned to the patient by i.v. infusion over about $2 \mathrm{hr}$. The entire procedure took $10 \mathrm{hr}$.

\section{Patient}

ACA, male, 43 yr old, was first admitted to Ramos Mejia Hospital on January 16th, 1982, with diffuse abdominal colic pain. He said that he used to smoke about 80 cigarettes daily, but stopped smoking 9 years ago, that he is a great coffee drinker, but does not drink any alcoholic beverages or drugs.

Since the age of 20 the patient has been directly exposed to lead, working for about 10 years in a smelting house and then as a plumber. Apparently there was no familial involvement. When he was 29 years old he was hospitalized for 15 days because of a sudden attack of intense headache, acute confusion, hallucinations, grand mal convulsion, vomiting, diplopia, ataxia. The symptoms disappeared after unknown medical treatment.

In 1974 he was again hospitalized twice with intense precordial pain first, followed by an acute abdominal colic. Because of the latter he underwent an operation, without precise diagnostic but 3 days later again had precordial pain being diagnosed as having diaphragmatic face infarct.

The patient was asymptomatic until June 1981 when recurrent abdominal pains reappeared with remission periods of 7 days. In this opportunity there was also slight motor paralysis in the legs, mostly on the right side; which remitted spontaneously. In September of the same year, the patient underwent cholecystectomy due to another colic attack; no improvement in his clinical condition was observed since then, therefore the patient was hospitalized in the Clinical Division, Unit B-4 of Ramos Mejia Hospital, on January 16th, 1982 as stated above.

\section{RESULTS AND DISCUSSION}

\section{Clinico-biochemical observations}

From complete clinical examinations and analysis, acute lead intoxication was suspected, the diagnosis was confirmed on the basis of excess urinary excretion of ALA and porphyrins, mainly Coproporphyrin (PBG was also slightly increased at admission), significantly decreased activity of erythrocyte ALA-D and augmented levels of $\mathrm{Pb}$ in blood (Table 1, 25/1/82). Typical basophilic stippling of the red blood cells, moderate anemia, reticulocytosis and the lead line on the gingival were also observed. Peripheral neuropathy has been documented by means of nerve conduction studies and electromyography. His abdominal colic was treated with dextrose solution $(10 \%)$ and calcium gluconate, leaving the hospital 2 weeks later. Sickness, nausea, vomiting, abdominal colics, general sense of malaise, myalgia, insomnia, including sexual impotence, related to his polyneuritis (already reported at the first admission) continued; therefore the patient was hospitalized again for quelation therapy on February 15th, 1982. Laboratory data are shown in Table 1. A total of 20 doses of BAL $(3 \mathrm{mg} / \mathrm{kg}$, i.m.), and i.v. infusion over $4 \mathrm{hr}$, of $\mathrm{Ca}-\mathrm{Na}_{2}$ EDTA (two $20 \%$ ampoules, in $500 \mathrm{ml}$ of dextrose $10 \%$, daily) during 8 days, were given.

The patient was discharged immediately after treatment without major changes in the urinary levels of precursors, $\mathrm{Pb}$ in blood or the activity of ALA-D, as can be seen in data corresponding to 5/4/82 and $26 / 4 / 82$ in Table 1 .

Although lead intoxication is an acquired disorder of porphyrin metabolism, a family study of some consanguineous relatives of the patient was carried out on the day of his second admission (Table 2). It was very interesting to find that his wife and three children (all of them living in the same house), although not showing any clinical symptoms, have low levels of ALA-D; particularly his two sons (cases 3 and 5), who helped him with the plumbing. The eldest son also has $\mathrm{Pb}$ levels above normal and both urinary precursors and porphyrins up to the highest normal limit. On the other hand, two sisters (cases 6 and 7) who live apart, showed no abnormality at all.

Table 1. Laboratory data of the patient

\begin{tabular}{|c|c|c|c|c|c|c|c|c|}
\hline \multirow[b]{2}{*}{ Date } & \multicolumn{2}{|c|}{ Urinary } & \multicolumn{3}{|c|}{$\begin{array}{l}\text { Urinary porphyrins } \\
\qquad(\mu \mathrm{g} / 24 \mathrm{hr})\end{array}$} & \multirow{2}{*}{$\begin{array}{c}\text { Fecal } \\
\text { porphyrins } \\
(\mu \mathrm{g} / \mathrm{g} \text { dry } w t)\end{array}$} & \multirow[b]{2}{*}{$\begin{array}{l}\text { ALA-D } \\
(\mathbf{U} / \mathrm{ml})\end{array}$} & \multirow[b]{2}{*}{$\begin{array}{c}\mathrm{Pb} \\
(\mu \mathrm{g} \%)\end{array}$} \\
\hline & $\begin{array}{c}\text { ALA } \\
(\mathrm{mg} / 24 \mathrm{hr})\end{array}$ & $\begin{array}{c}\text { PBG } \\
(\mathrm{mg} / 24 \mathrm{hr})\end{array}$ & URO & COPRO & Total & & & \\
\hline $25 / 1 / 82$ & 19.98 & 4.26 & 196.8 & 1740.6 & 1937.4 & 112.2 & 44 & 71 \\
\hline $15 / 2 / 82$ & 9.76 & 3.27 & 197.2 & 822.4 & 1019.6 & 117.9 & 27 & 105 \\
\hline $5 / 4 / 82$ & 8.65 & 2.27 & 130.1 & 622.6 & 752.8 & 66.3 & 58 & 123 \\
\hline $26 / 4 / 82$ & 9.41 & 2.99 & 23.9 & 306.2 & 330.1 & 340.2 & 83 & 125 \\
\hline Normals & $2-4$ & $1-2$ & - & — & $20-250$ & $30-130$ & $656 \pm 126$ & $0-35$ \\
\hline
\end{tabular}

Determinations were carried out as described in "Materials and Methods" 


\section{Application of enzyme replacement therapy}

Quelation therapy in this patient did not produce major benefit either clinically or biochemically. At the begining of December 1982 the laboratory data were much the same as those of previous studies; therefore we decided to apply enzyme replacement therapy by using ALA-D loaded RBC ghosts.

In spite of a number of attempts, enzyme therapy has not as yet been proved to be of practical use in the treatment of any human disease. However, we did consider that all the conditions were already established to be successful this time. As already stated, our preliminary studies in animals, showed that administration of ALA-D entrapped in RBC ghosts to lead intoxicated animals was absolutely safe and could overcome the biochemical defect, restoring the greatly reduced ALA-D activity to normal levels (Bustos et al., 1983b).

The patient was carefully informed about the new therapeutical trial and gave unequivocal consent.

On December 6th, the patient was then treated with $100 \mathrm{ml}$ of autologous RBCg loaded with 25,600 units of ALA-D. He was permanently controlled for the first $24 \mathrm{~h}$, enzyme infusion showed no effect on blood pressure, respiration rate, pulse, body temperature, or any other vital signs. No abnormalities in renal or liver function tests were observed either and not any other subjective symptoms were associated with the carrier-assisted delivery of ALA-D.

Samples of blood and urine were collected at different times during the first day, then blood, urine and feces, daily for 11 days and then every 3-4 days.

As is shown in Fig. 1, significant increase in his ALA-D activity was seen after $1 \mathrm{hr}$, a peak at $2 \mathrm{hr}$ was observed, followed by a $7-10 \%$ decrease at $4 \mathrm{hr}$, and then a constant recovery of activity at $16,24 \mathrm{hr}$, reaching its maximum 2 days after infusion, which was maintained for the next week. At day 10 the levels began to slowly diminish up to day 14 , when he was discharged, from then onwards the activity of ALA-D remained practically leveled off for the following 3 weeks.

We should note and emphasize here that, results obtained with the patient, exactly reproduced the animal response when using the RBC ghosts mode of ALA-D administration to lead intoxicated rats and mice, a peak of activity after $2 \mathrm{hr}$ of infusion was constantly observed (Bustos et al., 1983b).

It was also found that the urinary excretion of precursors and porphyrins returned rapidly to normal and the level of $\mathrm{Pb}$ in blood was reduced by about $45 \%$ (Figure 1 ).

Although it is often difficult to appraise subjective changes, rapid improvement was observed in our patient's activity status and in his feeling of wellbeing, during treatment. We have not detected any untoward side-effects, neither any abnormality in coagulation screening or liver function tests during or after infusion. He presented no symptoms and all clinical and biochemical parameters were normalized.

It is interesting to recall that since his first admission the patient complained of sexual impotence, after receiving ALA-D loaded RBC ghosts he said he has completely recovered his sexual capacity in full. We know that oral exposure to very low doses of $\mathrm{Pb}$ 


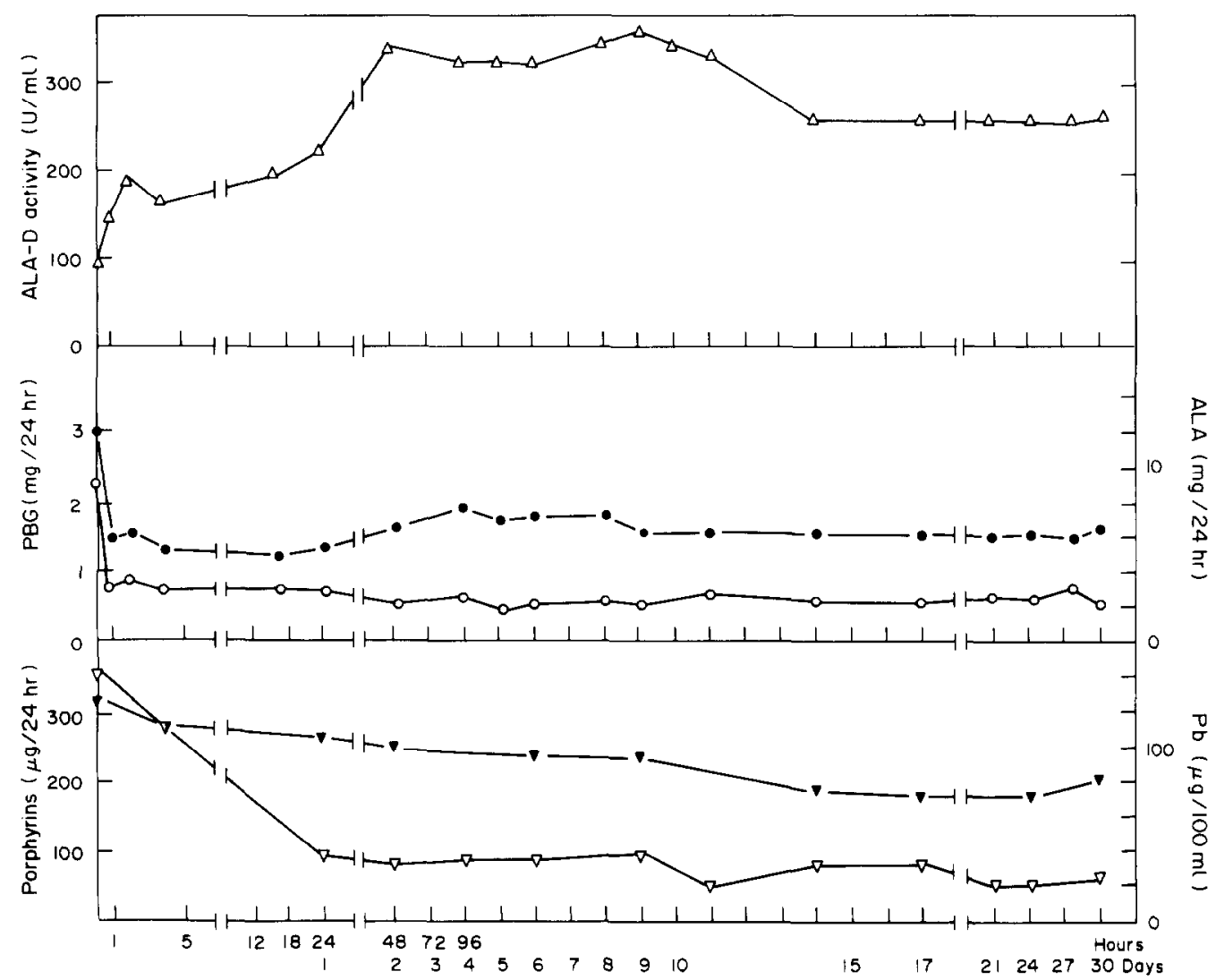

Fig. 1. Effect of enzyme replacement therapy with ALA-D loaded autologous erythrocyte ghosts in a patient with chronic lead intoxication on ALA-D levels $(\triangle)$, urinary ALA $(O)$, urinary PBG $(0)$, urinary porphyrins $(\nabla)$ and $\mathrm{Pb}$ in blood $(\nabla)$. The patient received only one course of enzyme at 0 time. Experimental details are given in the text.

$(2 \mu / \mathrm{kg}$ body wt) causes damage to spermatogenesis and to RNA synthesis in the cell division phase (Egarova et al., 1966) and andrological disturbances with sexual disfunction have been reported in men exposed to leaded gasoline (Neshkov, 1971) and inorganic lead (Lancranjean et al., 1975). On the other hand, removal of polyvalent metals, including lead, by means of quelation, drastically increases the life span of spermatozoa (Bjorksten, 1968). The recovery of sexual function in our patient is another clear sign of the benefit produced by the therapy and we might speculate that the burden of ALA-D given in the RBC ghosts has not only metabolized the excess ALA and restored the enzyme levels to nearly normal, but it is also possible that part of the enzyme has been acting as a kind of quelate, sequestrating the circulating $\mathbf{P b}$.

It is very likely that infusion of larger amounts of enzyme would be even more effective in the management of the disease, probably magnifying the effects observed here; for instance further decreasing the levels of $\mathrm{Pb}$ in blood.

\section{CONCLUSIONS}

It has been stated that enzyme replacement therapy is a promising therapeutic approach which nevertheless had not as yet been achieved (Beutler, 1981).

Erythrocyte ghosts have many of the attributes of the ideal carrier for enzymes (Ihler, 1979), one very important attribute is that the patient's own blood may be used. However, so far, the only report of its application in a human clinical trial has been the unsuccessful attempt to treat Gaucher's disease by administration of glucocerebrosidase encapsulated in human red cells coated with gammaglobulin (Beutler et al., 1977). In an interesting paper the authors demonstrated the safety of the treatment, although the results obtained had been of doubtful benefit, in a patient with far-advanced disease, who finally died.

Our preliminary studies in animal models (Bustos et al., 1983b) were very encouraging indeed and prompted us to initiate replacement therapy with ALA-D in a chronic case of lead intoxication, because, obviously, clinical efficacy must only be evaluated in clinical trials.

As far as we know this is the first successful human clinical application of the use of an enzyme encapsulated in erythrocyte ghosts for treating a disease.

The present studies have been confined to the use of autologous red cells, however donor cells can also be used for enzyme entrapment.

The current treatment of lead intoxication involves chelation therapy, very often with agents such as BAL, EDTA or penicillamine, which are very hazardous, so care should be taken on the possible toxic effects of the medication. The treatment proposed here is relatively free of side effects. 
Our results indicate that a number of lead intoxicated patients could benefit from this new form of therapy.

Acknowledgements - A. M. Stella, E. A. Wider and Alcira M. del C. Batlle hold the post of Scientific Research in the Argentine National Research Council (CONICET) and N. L. Bustos is a Research fellow at the CONICET. This work was supported by grants from the CONICET, the SECYT, Secretaría de Salud Pública del Ministerio de Bienestar Social and Banco de la Nación Argentina. We are also very grateful to Dr J. Capdeville, Chief Division of the Department of Clinical Medicine, Ramos Mejia Hospital, for his support and Drs R. De Gregorio and $\mathbf{J}$. Cassetti from the same Department for their collaboration in the ward. Our thanks are also due to Dr Morando from the Hemoterapic Department for blood supply, to Dr E. Gobbi from the National Institute of Chemistry for lead determinations in blood, and to Dr H. Torres and Dr L. F. Leloir for kindly providing sterile settlings. This paper forms part of the Doctoral Thesis of N. L. Bustos to be submitted to the Lniversity of Buenos Aires for her Ph.D. degree.

\section{REFERENCES}

Batlle A. M. del C., Ferramola A. M. \& Grinstein M. (1967) Purification and general properties of delta aminolaevulic acid dehydratase from cow liver. Biochem. $J .104$, 244-249.

BfutLer E. (1981) Enzyme replacement therapy. Trends biochem. Sci. 6, 95-97.

Beutlfr E., Dale G. L., Guinto E. \& Kehl W. (1977) Enzyme replacement therapy in Gaucher's disease: Preliminary clinical trial of a new enzyme preparation. Proc. natn. Acad. Sci. U.S.A. 74, 4620-4623.

BJORKSTEN J. (1968) The crosslinking theory of aging. $J$. Am. geriatr. Soc. 16, 408-427.

Bustos N. L., Stella A. M., Widfr de Xifra E. A. \& BATLLE A. M. DEL C. (1980) Studies on erythrocyte aminolaevulinate dehydratase I. Its purification and possible therapeutic applications. Int. J. Biochem. 12, 745-749.

Bustos N. L.. Stella A. M., Wider E. A. \& Batlle
A. M. DEL C. (1983a) Enzyme replacement therapy in Porphyrias--III. Potential use of erythrocyte ghosts as carriers of $\delta$-aminolaevulinate dehydratase. Int. J. Biochem. 15, 447-452.

Bustos N. L.. Strlla A. M., Wider E. A. \& Batlli: A. M. DEL C. (1983b) Enzyme replacement therapy in Porphyrias $\mathrm{V}$ : In vivo correction of $\dot{\delta}$-aminolaevulinate dehydratase defective erythrocytes in lead intoxicated animals by enzyme-loaded erythrocyte ghosts. In preparation.

Egorova G. M.. IVAnov M. G. \& SanotskiJ I. V. (1966) Specificity of the effect of lead on spermatogenesis. In Toksikologiva Novykh Promyshlennykh Khimicheskikh Veshchestv (Edited by Letavet A. A. and Sanotskij I. Y.) Vol. III, pp, 33-41. Meditsena, Moscow.

Espinola L. C.. Widle E. A.. Stllla A. M. \& Batlll: A. M. DEL C. (1983) Enzyme replacement therapy in Porphyrias-II. Entrapment of $\delta$-aminolaevulinate dehydratase in liposomes. Int. J. Biochem. 15, 439-445.

IhLI:R G. M. (1979) Potential use of erythrocytes as carriers for enzymes and drugs. In Drug Carriers in Biology and Medicine (Edited by Gregoriadis G.) pp. 129-153. Academic Press, New York.

Kesten E. M., Stella A. M. Wider E. \& Batlli: A. M. DEL C. (1980) Effect of cadmium on porphyrin biosynthesis I. Int. J. Biochem. 12. 905908.

Lancranjean I.. Popescu H.. Gavaniscu O.. Klepsch J. \& SFrbanescu M. (1975) Reproduction ability of workmen occupationally exposed to lead. Archs envir. Hith 30, 396-401.

Mauzerall D. \& Granick S. (1976) The occurrence and determination of $\delta$-aminolaevulinic acid and porphobilinogen in urine. J. biol. Chem. 219, 435-446.

NFSHKou N.S. (1971) The influence of chronic intoxications with leaded-gasoline on spermatogenesis and sexual functions in man. Gig. Truda prof. Zabol. 15, 45-49.

Rimington C. (1971) Quantitative determination of porphobilinogen and porphyrins in faeces and erythrocytes. Ass. clin. Path-Broadsheet 70 (Revised Broadsheet 36).

Ryman B. E. (1977) Enzymes in therapy. In Enzymes in Health and Disease, Inaug. Sci. Mcet. Int. Soc. clin. Enzym., London, pp. 222-227. Karger, Basel (1978). 